\title{
Could Acting Training Improve Social Cognition and Emotional Control?
}

\author{
Brennan McDonald ${ }^{1 *}$, Thalia R. Goldstein ${ }^{2}$ and Philipp Kanske ${ }^{1,3}$ \\ ${ }^{1}$ Clinical Psychology and Behavioral Neuroscience, Faculty of Psychology, Technische Universität Dresden, Dresden, \\ Germany, ${ }^{2}$ Department of Psychology, George Mason University, Fairfax, VA, United States, ${ }^{3}$ Max Planck Institute for Human \\ Cognitive and Brain Sciences, Leipzig, Germany
}

Keywords: theory of mind, empathy, mentalizing, emotion regulation, perspective-taking

OPEN ACCESS

Edited by:

Corinne Jola

Abertay University, United Kingdom

Reviewed by:

Iris Trinkler,

Université de Strasbourg, France Melike Marethe Fourie,

Stellenbosch University, South Africa

Ruth Levin-Vorster,

University of Cape Town,

South Africa, in collaboration with

reviewer MF

*Correspondence:

Brennan McDonald

brennan.mcdonald@

mailbox.tu-dresden.de

Specialty section:

This article was submitted to

Cognitive Neuroscience,

a section of the journal

Frontiers in Human Neuroscience

Received: 30 December 2019

Accepted: 04 August 2020

Published: 23 September 2020

Citation:

McDonald B, Goldstein TR and Kanske $P$ (2020) Could Acting Training

Improve Social Cognition and

Emotional Control?

Front. Hum. Neurosci. 14:348.

doi: 10.3389/fnhum.2020.00348
Acting is fascinating from psychological and neuroscientific perspectives, as it involves an individual creating an endogenously generated, accurate physical and verbal performance of another's emotional and cognitive states. However, despite the popularity of acting, the practice has received limited interest from cognitive neuroscience (Goldstein and Bloom, 2011, although see Brown et al., 2019), while other art forms have raised much greater attention, including music (e.g., Koelsch, 2014), visual art (e.g., Bolwerk et al., 2014), literature (e.g., Jacobs, 2015), poetry (e.g., Zeman et al., 2013), and dance (e.g., Karpati et al., 2017). Nevertheless, acting requires a range of social, cognitive and affective skills of concern to neuroscience, including memory, verbal ability, emotional control and social cognitive processes like empathy and Theory of Mind (ToM; Noice and Noice, 2006; Goldstein and Winner, 2012; Winner et al., 2013).

Two questions are of particular interest: (i) What are the neural mechanisms that allow actors to produce realistic performances of characters other than themselves? (ii) What long-term impact does acting training have on (social) neurocognition? Following Goldstein and Winner (2012), we explore how neuroscientific research into ToM, empathy, and emotional processing, is beginning to illuminate how actors manifest characters. Additionally, we propose that engagement with acting may in turn improve social competencies by inducing changes in the neural networks underlying social cognition.

\section{APPROACHES TO ACTING}

Debate over which techniques allow actors to produce realistic performances has a long history, with numerous schools theorizing and prescribing methods for acting practice (for review see Noice and Noice, 2013; Gallagher and Gallagher, 2019). These include debates surrounding whether an actor should (i) understand/elaborate on a character's mental life, draw on personal experience and replicate the emotions of the character during performance (Stanislavski, 2013), (ii) remain detached, perfecting and portraying the character's outward behaviors (Diderot, 1957), or (iii) actively embody the character, truthfully experiencing emotions within the imaginary world of the performance (Meisner and Longwell, 1987). Importantly, the approach an actor takes to create and perform a character will likely influence the cognitive and affective processes involved. As our intent is to provide a brief commentary on neuroscience's role in understanding acting, we avoid committing to any specific approach, instead understanding acting in the broadest sense as the art or practice of representing a character for the purpose of performance (Merriam-Webster., 2018). However, it is worth keeping in mind that many approaches to acting exist and that future neuroscientific research on acting must take this into account. 


\section{THEORY OF MIND AND EMPATHY}

The ability to represent others' mental states, referred to as ToM or cognitive empathy, plays a critical role in understanding and navigating social situations (Frith and Frith, 2006). ToM represents a socio-cognitive phenomenon, involving abstract, propositional knowledge about another's mental state (Happe et al., 2017; Kanske, 2018; Preckel et al., 2018). Depending on the actor's approach to character performance, reflection into the character's mental life may be important part of the character creation process, involving exploration of the history, motivations, beliefs and values of the person to be portrayed, often going well beyond the information contained within the script (Noice and Noice, 2013). In other words, for many actors, creating a character involves the complex application of ToM. Brain regions involved in ToM include superior temporal sulcus, temporal poles, medial prefrontal cortex, temporoparietal junction, and posterior cingulate/precuneus (Schurz et al., 2014). Additionally, ventromedial prefrontal cortex and temporoparietal junction are implicated in self/other processing and judgments (Denny et al., 2012) and it has been suggested that overcoming self-other interference and ToM are deeply integrated processes (Qureshi et al., 2020). Moreover, simulating others has been shown to influence selfknowledge, with trait and memory measures becoming similar to a simulated other after adopting their perspective (Meyer et al., 2019). In relation to acting, a recent neuroimaging study demonstrated that when trained actors answered questions from the first-person fictional perspective of a character, in contrast to their own perspective, dorsomedial prefrontal cortex/superior frontal gyrus and ventromedial prefrontal cortex are deactivated, suggesting acting may involve the suppression of self-processing (Brown et al., 2019). Concurrently, increased activation was found in the precuneus, a region belonging to the brain's dorsal attentional network, involved in episodic retrieval, attentional orienting, and visual imagery (Fletcher et al., 1995; Cavanna and Trimble, 2006; Spreng et al., 2010). Interestingly, a similar pattern of deactivation in prefrontal regions was observed when the actors were asked to respond to questions in their own perspective while adopting a British accent compared to no accent; however, no precuneus activation was observed for this contrast. Brown and colleagues interpret this finding by suggesting that the pretense of adopting an (unspecified) other's attributes may require suppression of the self, while acting out a specified character could require an additional dispersion of self-related attentional resources. Interestingly, they relate this proposed dispersion to the idea of split or duel consciousness, an important concept in acting theory (Diderot, 1957; Stanislavski, 2013), describing the constant shifting of an actor's attention between the conscious awareness of the self during the performance and the perspective of the character existing in the world of the play. Brown et al. thus argue that precuneus activation may reflect the attentional maintenance of the actor's identity as a conscious self while adopting the fictional character's perspective.

In contrast to ToM, empathy (also referred to as emotional or affective empathy) has been defined as sharing or mirroring the feelings of another, while being aware that the emotion originates from another person (De Vignemont and Singer, 2006). Neurally, empathy involves activation of the same brain networks during the shared emotion as would be active during a first-hand experience (Gallese, 2003; Wicker et al., 2003; Singer and Lamm, 2009). For example, the experience of pain and witnessing another experiencing pain results in the activation of a core network consisting of the anterior insula and anterior cingulate cortex (Singer et al., 2004; Jackson et al., 2005; CorradiDell'Acqua et al., 2016). Importantly, neuroimaging evidence has demonstrated that the underlying neural mechanisms involved in empathy and ToM are distinct and separately contribute to social competencies (Blair, 1995, 2005; Kanske et al., 2015, 2016). The role of empathy in acting practice has long been an important point of theoretical discussion (for review see Gallagher and Gallagher, 2019). Moreover, empirical work suggests that acting training may improve behavioral measures of empathy (Goldstein and Winner, 2012). However, the means by which the neural networks underlying empathy are recruited/altered during acting remain unknown. Given the perceived importance of empathy in acting practice, a neuroimaging approach may offer novel insight into the role socio-affective phenomena play during dramatic performance.

\section{EMOTION REGULATION AND GENERATION}

During performance an actor must portray a character, including facial expressions, vocal inflection, movement, and body language. In addition, the actor often has to reflect and respond to other performers on stage. Under these conditions, an actor must not only empathize with and take the perspective of the character, but also regulate and spontaneously generate appropriate emotional states. The process of emotion regulation involves altering ongoing emotional states by employing regulatory cognitive processes; including producing changes in attention and applying cognitive control strategies (Gross, 1998, 2002; Ochsner and Gross, 2005; Kanske et al., 2011). Importantly, and depending on circumstance, there are more or less adaptive/dysfunctional ways of regulating emotions (e.g., acceptance or suppression of an emotional experience) and successful emotion regulation is linked to a range of psychological, social and physical health outcomes (Gross, 2002, 2008). For example, Gross and Levenson (1993) demonstrated that the sympathetic nervous system activity of individuals instructed not to show emotion through facial expressions when presented with disgusting stimuli was higher than in individuals allowed to display disgust through their face, thus suggesting that acceptance of negative emotions may be more beneficial than emotional suppression. Additionally, studies have begun to demonstrate that affective responses may be modified by consciously taking the perspective of other people (i.e., ToM; Gilead et al., 2016; McDonald et al., 2020). For example, Gilead and colleagues showed that activity in the medial prefrontal cortex and amygdala of participants taking the perspective of either a sensitive/squeamish or tough/resilient individual 
differentially simulated the expected negative affective state of the target. This finding suggests that taking another's perspective impacts our own ability to regulate and experience emotions. Given that actors must regulate their emotions when rehearsing and performing a character, we propose that they may be more proficient in adopting and utilizing emotion regulation strategies. In a similar vein, Goldstein et al. (2009) has suggested that actors are likely to be more accepting of their emotions and less likely engage in emotional suppression. Goldstein et al. (2013) found that a year of acting practice decreased the use of emotional suppression in children aged 7-10, while adolescents majoring in acting at high school (compared to other art majors e.g., music) used less suppression. Additionally, 4-5-years olds randomly assigned to an 8-week drama condition (compared to block building or reading) showed increased emotional control (i.e., inhibition of affective responses to observed or discussed distress; Goldstein and Lerner, 2018).

Complementary to the process of emotion regulation is the process of endogenous emotion generation, which involves emotions being experienced by an individual as a result of internal cognitive and affective processes, often in the absence of external stimuli. In the context of acting, emotion generation is usually a very deliberate, voluntary process occurring in the specific contexts of a performance, often with other actors present (Noice and Noice, 2013). Engen et al. (2017) examined participants endogenously generating emotions during functional neuroimaging and found that the brain's salience network (involved in detecting and filtering task-relevant stimuli; Seeley et al., 2007), including the anterior insula and dorsomedial prefrontal cortex, as well as basal ganglia and midbrain structures, were implicated in initial affect generation. In contrast, default mode and frontoparietal control networks (implicated primarily in non-task related, resting states and cognitive control processes, respectively; Spreng et al., 2010) were involved in elevated affect even after active generation had ceased, with the emotional states only being deactivated when suppressed by the participants. These findings thus demonstrate that people are in principle capable of spontaneously generating emotional states, as well as manipulating and regulating their emotions by adopting another's perspective.

Importantly, however, actors vary in the techniques used to portray the emotions of a character. If an actor is inclined to actively embody the character's emotional state this will likely require different emotion regulation/generation strategies and neural processes (e.g., De Gelder, 2006; Niedenthal, 2007; Nummenmaa et al., 2014) than an actor that uses simulation to portray the emotional behaviors (e.g., Decety and Grèzes, 2006). Thus, any comprehensive understanding of emotion regulation and generation in actors must take into account the actor's approach to performing emotions. Based on this, a goal of future research should be to examine the neural underpinnings and overall impact of emotional processing across the acting experience. Finally, acting could also present a means to examine the complex interplay between bottom-up empathic mirroring of emotions and top-down emotional regulation, which partially share underlying neural circuitry (Singer and Lamm, 2009; Ochsner et al., 2012) and may be deeply interconnected processes.

\section{THE IMPACT OF ACTING}

A growing body of evidence shows that socio-affective and socio-cognitive brain networks are principally plastic, with interventions such as mental training practices (e.g., affect- or metacognition-focused meditation) inducing changes in cortical morphology (Valk et al., 2017; Trautwein et al., 2020). With respect to acting, Schellenberg (2004) showed that 6-year-old children assigned with 6 weeks of acting training had improved behavioral ToM measures compared to children assigned to 6 weeks of music practice. Similarly, Goldstein et al. (2009) showed that adolescent and adult actors have above average skill in ToM tasks, but not above average levels of empathy. Somewhat contrasting with this result, Goldstein and Winner (2012) followed children and adolescents receiving 1 year of either acting or other arts training (i.e., visual arts, music) and assessed empathy and ToM before and after training. In both groups, those receiving acting (but not other arts) training showed significant gains in empathy and ToM. Additionally, Nettle (2006) demonstrated that actors score slightly higher levels of empathy than non-actor controls. These findings suggest that both ToM and empathy may be amenable to improvement through acting training, however, a goal of further research should be to tease apart the conditions (e.g., age, acting experience, acting techniques, personality measures) under which such improvements occur.

Based on these initial findings, we propose that actors, by repeatedly engaging the first-person fictional perspective required to produce a character, may induce changes to the cortical networks underlying social cognition. Such changes could occur as the result of Hebbian learning mechanisms which involve the strengthening of neural network functional and effective connectivity due to frequent network engagement (Keysers and Gazzola, 2006). Moreover, specific strengthening of these social networks may crucially contribute to improvements in an actor's ability to portray a particular character. Finally, by engaging in different characters on a regular basis, an actor is exposing the networks underlying ToM, empathy and emotional processing to a broad variety of novel social stimuli. It is via repeated exposure that, we contend, generalized improvements in social cognitive abilities arise from prolonged engagement with acting.

Taken together, these initial behavioral studies suggest that engagement in acting training may indeed improve aspects of social cognition. Given that many mental disorders involve impairments in social cognition (Gallagher and Varga, 2015) and that social abilities are important in both educational and business settings (Blakemore, 2010; Hülsheger and Schewe, 2011), we suggest that future research into acting's psychological impact may offer new avenues to understand and improve social skills. For example, there is a burgeoning literature exploring theatrical techniques as a possible intervention for autism spectrum disorders (Corbett et al., 2011, 2019; Gabriel et al., 2016), while a recent study showed 6 weeks of improve theater training produced increased creativity and psychological wellbeing in participants (Schwenke et al., 2020). Finally, we promote a broader discussion between the fields of acting theory/pedagogy 
and cognitive neuroscience, as we believe exchange between these disciplines will provide both a deeper understanding of the actor's craft as well as motivate novel insights into the neural networks underlying ToM, empathy and emotional processing.

\section{AUTHOR CONTRIBUTIONS}

$\mathrm{BM}, \mathrm{TG}$, and PK contributed to the conception and writing of this review. BM prepared the draft for submission. All authors contributed to the article and approved the submitted version.

\section{REFERENCES}

Blair, R. J. R. (1995). A cognitive developmental approach to morality: Investigating the psychopath. Cognition 57, 1-29. doi: 10.1016/0010-0277(95)00676-P

Blair, R. J. R. (2005). Responding to the emotions of others: Dissociating forms of empathy through the study of typical and psychiatric populations. Conscious. Cogn 14, 698-718. doi: 10.1016/j.concog.2005.06.004

Blakemore, S. J. (2010). The developing social brain: implications for education. Neuron 65, 744-747. doi: 10.1016/j.neuron.2010.03.004

Bolwerk, A., Mack-Andrick, J., Lang, F. R., Dörfler, A., and Maihöfner, C. (2014). How art changes your brain: Differential effects of visual art production and cognitive art evaluation on functional brain connectivity. PLOS ONE 9:e101035. doi: 10.1371/journal.pone.0101035

Brown, S., Cockett, P., and Yuan, Y. (2019). The neuroscience of Romeo and Juliet: an fMRI study of acting. R. Soc. Open Sci. 6:181908. doi: 10.1098/rsos.181908

Cavanna, A. E., and Trimble, M. R. (2006). The precuneus: a review of its functional anatomy and behavioural correlates. Brain 129, 564-583. doi: 10.1093/brain/awl004

Corbett, B. A., Gunther, J. R., Comins, D., Price, J., Ryan, N., Simon, D., et al. (2011). Brief report: theatre as therapy for children with autism spectrum disorder. J. Autism Dev. Disord. 41, 505-511. doi: 10.1007/s10803-010-1064-1

Corbett, B. A., Ioannou, S., Key, A. P., Coke, C., Muscatello, R., Vandekar, S., et al. (2019). Treatment effects in social cognition and behavior following a theaterbased intervention for youth with Autism. Dev. Neuropsychol. 44, 481-494. doi: $10.1080 / 87565641.2019 .1676244$

Corradi-Dell'Acqua, C., Tusche, A., Vuilleumier, P., and Singer, T. (2016). Cross-modal representations of first-hand and vicarious pain, disgust and fairness in insular and cingulate cortex. Nat. Commun. 7:10904. doi: 10.1038/ncomms10904

De Gelder, B. (2006). Towards the neurobiology of emotional body language. Nat. Rev. Neurosci. 7, 242-249. doi: 10.1038/nrn1872

De Vignemont, F., and Singer, T. (2006). The empathic brain: how, when and why?. Trends Cogn. Sci. (Regul. Ed) 10, 435-441. doi: 10.1016/j.tics.2006.08.008

Decety, J., and Grèzes, J. (2006). The power of simulation: imagining one's own and other's behavior. Brain Res. 1079, 4-14. doi: 10.1016/j.brainres.2005. 12.115

Denny, B. T., Kober, H., Wager, T. D., and Ochsner, K. N. (2012). A meta-analysis of functional neuroimaging studies of self-and other judgments reveals a spatial gradient for mentalizing in medial prefrontal cortex. J. Cogn. Neurosci. 24, 1742-1752. doi: 10.1162/jocn_a_00233

Diderot, D. (1957). The Paradox of the Actor (L. Strasberg, Intro; H. Irving, Preface). New York, NY: Hill \& wang. (Original work published in 1770).

Engen, H. G., Kanske, P., and Singer, T. (2017). The neural component-process architecture of endogenously generated emotion. Soc Cogn Affect Neurosci. 12, 197-211. doi: 10.1093/scan/nsw108

Fletcher, P. C., Frith, C. D., Baker, S. C., Shallice, T., Frackowiak, R. S., and Dolan, R. J. (1995). The mind's eye-precuneus activation in memory-related imagery. Neuroimage 2, 195-200. doi: 10.1006/nimg.1995. 1025

Frith, C. D., and Frith, U. (2006). The neural basis of mentalizing. Neuron 50, 531-534. doi: 10.1016/j.neuron.2006.05.001

Gabriel, J., Angevin, E., Rosen, T., and Lerner, M. D. (2016). "Use of theatrical techniques and elements as interventions for autism spectrum disorders," in

\section{FUNDING}

PK was supported by the German Federal Ministry of Education and Research within the ASD-Net (BMBF FKZ 01EE1409A), the German Research Foundation (KA 4412/21, KA 4412/4-1, KA 4412/5-1, INST 269/869-1), and Die Junge Akademie at the Berlin-Brandenburg Academy of Sciences and Humanities and the German National Academy of Sciences Leopoldina. BM was supported by the Saxon Scholarship Program.
Theater and Cognitive Neuroscience, eds G. Sofia, J. Lutterbie, N. Shaughnessy, C. Falletti, and V. Jacono, 163-177.

Gallagher, S., and Gallagher, J. (2019). Acting oneself as another: An actor's empathy for her character. Topoi 39, 779-790.

Gallagher, S., and Varga, S. (2015). Social cognition and psychopathology: a critical overview. World Psychiatry 14, 5-14. doi: 10.1002/wps.20173

Gallese, V. (2003). The roots of empathy: the shared manifold hypothesis and the neural basis of intersubjectivity. Psychopathology 36, 171-180. doi: $10.1159 / 000072786$

Gilead, M., Boccagno, C., Silverman, M., Hassin, R. R., Weber, J., and Ochsner, K. N. (2016). Self-regulation via neural simulation. Proc. Natl. Acad. Sci. U.S.A. 113, 10037-10042. doi: 10.1073/pnas.1600159113

Goldstein, T. R., and Bloom, P. (2011). The mind on stage: why cognitive scientists should study acting. Trends Cogn. Sci. (Regul. Ed) 15, 141-142. doi: 10.1016/j.tics.2011.02.003

Goldstein, T. R., and Lerner, M. D. (2018). Dramatic pretend play games uniquely improve emotional control in young children. Dev. Sci. 21:e12603. doi: $10.1111 /$ desc. 12603

Goldstein, T. R., Tamir, M., and Winner, E. (2013). Expressive suppression and acting classes. Psychol. Aesth. Creat. Arts 7:191. doi: 10.1037/a0030209

Goldstein, T. R., and Winner, E. (2012). Enhancing empathy and theory of mind. J. Cogn. Dev. 13, 19-37. doi: 10.1080/15248372.2011.573514

Goldstein, T. R., Wu, K., and Winner, E. (2009). Actors are skilled in theory of mind but not empathy. Imagin. Cogn. Pers. 29, 115-133. doi: 10.2190/IC.29.2.c

Gross, J. J. (1998) The emerging field of emotion regulation: an integrative review. Rev. Gen. Psychol. 2, 271-299 doi: 10.1037/1089-2680.2.3.271

Gross, J. J. (2002). Emotion regulation: Affective, cognitive, and social consequences. Psychophysiology 39, 281-291. doi: 10.1017/S0048577201393198

Gross, J. J. (2008). "Emotion regulation," in: Handbook of emotions. 3rd ed., eds M. Lewis, J. M. Haviland-Jones, and L. F. Barrett (New York, NY: The Guilford Press), 497-513.

Gross, J. J., and Levenson, R. W. (1993). Emotional suppression: physiology, self-report, and expressive behavior. J. Pers. Soc. Psychol. 64, 970-986. doi: 10.1037//0022-3514.64.6.970

Happe, F., Cook, J. L., and Bird, G. (2017). The Structure of Social Cognition: In(ter)dependence of Sociocognitive Processes. Annu. Rev. Psychol. 8, 243-67 doi: 10.1146/annurev-psych-010416-044046

Hülsheger, U. R., and Schewe, A. F. (2011). On the costs and benefits of emotional labor: a meta-analysis of three decades of research. J. Occup. Health Psychol. 16:361. doi: $10.1037 / \mathrm{a} 0022876$

Jackson, P. L., Meltzoff, A. N., and Decety, J. (2005). How do we perceive the pain of others? A window into the neural processes involved in empathy. Neuroimage 24, 771-779. doi: 10.1016/j.neuroimage.2004.09.006

Jacobs, A. M. (2015). Neurocognitive poetics: methods and models for investigating the neuronal and cognitive-affective bases of literature reception. Front. Hum. Neurosci 9:186. doi: 10.3389/fnhum.2015.00186

Kanske, P. (2018). The social mind: disentangling affective and cognitive routes to understanding others. Interdisc. Sci. Rev. 43, 115-124. doi: 10.1080/03080188.2018.1453243

Kanske, P., Böckler, A., Trautwein, F. M., Parianen Lesemann, F. H., and Singer, T. (2016). Are strong empathizers better mentalizers? Evidence for independence and interaction between the routes of social cognition. Soc. Cogn. Affect. Neurosci. 11, 1383-1392. doi: 10.1093/scan/nsw052 
Kanske, P., Böckler, A., Trautwein, F. M., and Singer, T. (2015). Dissecting the social brain: introducing the EmpaToM to reveal distinct neural networks and brain-behavior relations for empathy and theory of mind. Neuroimage 122, 6-19. doi: 10.1016/j.neuroimage.2015.07.082

Kanske, P., Heissler, J., Schönfelder, S., Bongers, A., and Wessa, M. (2011). How to regulate emotion? Neural networks for reappraisal and distraction. Cerebral Cortex 21, 1379-1388. doi: 10.1093/cercor/bhq216

Karpati, F. J., Giacosa, C., Foster, N. E., Penhune, V. B., and Hyde, K. L. (2017). Dance and music share gray matter structural correlates. Brain Res. 1657, 62-73. doi: 10.1016/j.brainres.2016.11.029

Keysers, C., and Gazzola, V. (2006). Towards a unifying neural theory of social cognition. Prog. Brain Res. 156, 379-401. doi: 10.1016/S0079-6123(06)56021-2

Koelsch, S. (2014). Brain correlates of music-evoked emotions. Nat. Rev. Neurosci. 15, 170-180. doi: $10.1038 / \mathrm{nrn} 3666$

McDonald, B., Becker, K., Meshi, D., Heekeren, H. R., and von Scheve, C. (2020). Individual differences in envy experienced through perspective-taking involves functional connectivity of the superior frontal gyrus. Cogn. Affect. Behav. Neurosci. 20, 783-797. doi: 10.3758/s13415-020-00802-8

Meisner, S., and Longwell, D. (1987). Sanford Meisner on Acting. New York, NY: Random House USA Inc.

Merriam-Webster. (2018). Definition of the Noun, Acting. Available onlin at: https://www.merriam-webster.com/dictionary/acting> (accessed May 09, 2020).

Meyer, M. L., Zhao, Z., and Tamir, D. I. (2019). Simulating other people changes the self. J. Exp. Psychol. Gen. 148, 1898-1913. doi: 10.1037/xge0000565

Nettle, D. (2006). Psychological profiles of professional actors. Pers. Individ. Dif. 40, 375-383. doi: 10.1016/j.paid.2005.07.008

Niedenthal, P. M. (2007). Embodying emotion. Science 316, 1002-1005. doi: $10.1126 /$ science. 1136930

Noice, H., and Noice, T. (2006). What studies of actors and acting can tell us about memory and cognitive functioning. Curr. Dir. Psychol. Sci. 15, 14-18. doi: 10.1111/j.0963-7214.2006.00398.x

Noice, T., and Noice, H. (2013). Practice and Talent in Acting. 309-331. The Complexity of Greatness: Beyond Talent Or Practice, Oxford University Press. doi: 10.1093/acprof:oso/9780199794003.003.0015

Nummenmaa, L., Glerean, E., Hari, R., and Hietanen, J. K. (2014). Bodily maps of emotions. Proc. Natl. Acad. Sci. U.S.A. 111, 646-651. doi: $10.1073 /$ pnas.1321664111

Ochsner, K. N., and Gross, J. J. (2005). The cognitive control of emotion. Trends Cogn. Sci. (Regul. Ed) 9, 242-249. doi: 10.1016/j.tics.2005.03.010

Ochsner, K. N., Silvers, J. A., and Buhle, J. T. (2012). Functional imaging studies of emotion regulation: a synthetic review and evolving model of the cognitive control of emotion. Annals N. Y. Acad. Sci. 1251, E1-E24. doi: 10.1111/j.1749-6632.2012.06751.x

Preckel, K., Kanske, P., and Singer, T. (2018). On the interaction of social affect and cognition: empathy, compassion and theory of mind. Curr. Opin. Behav. Sci. 19, 1-6. doi: 10.1016/j.cobeha.2017.07.010

Qureshi, A. W., Monk, R. L., Samson, D., and Apperly, I. A. (2020). Does interference between self and other perspectives in theory of mind tasks reflect a common underlying process? Evidence from individual differences in theory of mind and inhibitory control. Psychon. Bull. Rev. 27, 178-190. doi: $10.3758 /$ s13423-019-01656-Z
Schellenberg, E. G. (2004). Music lessons enhance IQ. Psychol. Sci 15, 511-514. doi: 10.1111/j.0956-7976.2004.0 0711.x

Schurz, M., Radua, J., Aichhorn, M., Richlan, F., and Perner, J. (2014). Fractionating theory of mind: a meta-analysis of functional brain imaging studies. Neurosci. Biobehav. Rev. 42, 9-34. doi: 10.1016/j.neubiorev.2014 01.009

Schwenke, D., Dshemuchadse, M., Rasehorn, L., Klarhölter, D., and Scherbaum, S. (2020). Improv to improve: the impact of improvisational theater on creativity, acceptance, and psychological well-being. J. Creat. Mental Health 1-18.

Seeley, W. W., Menon, V., Schatzberg, A. F., Keller, J., Glover, G. H., Kenna, H., et al. (2007). Dissociable intrinsic connectivity networks for salience processing and executive control. J. Neurosci. 27, 2349-2356. doi: 10.1523/JNEUROSCI.5587-06.2007

Singer, T., and Lamm, C. (2009). The social neuroscience of empathy. Ann. N. Y. Acad. Sci. 1156, 81-96. doi: 10.1111/j.1749-6632.2009.04418.x

Singer, T., Seymour, B., O'doherty, J., Kaube, H., Dolan, R. J., and Frith, C. D. (2004). Empathy for pain involves the affective but not sensory components of pain. Science 303, 1157-1162. doi: 10.1126/science.1093535

Spreng, R. N., Stevens, W. D., Chamberlain, J. P., Gilmore, A. W., and Schacter, D. L. (2010). Default network activity, coupled with the frontoparietal control network, supports goal-directed cognition. Neuroimage 53, 303-317. doi: 10.1016/j.neuroimage.2010.06.016

Stanislavski, C. (2013). An Actor Prepares. London: Bloomsbury Publishing PLC.

Trautwein, F. M., Kanske, P., Böckler, A., and Singer, T. (2020). Differential benefits of mental training types for attention, compassion, and theory of mind. Cognition 194:104039. doi: 10.1016/j.cognition.2019. 104039

Valk, S. L., Bernhardt, B. C., Trautwein, F. M., Böckler, A., Kanske, P., Guizard, N., et al. (2017). Structural plasticity of the social brain: Differential change after socio-affective and cognitive mental training. Sci. Adv. 3:e1700489. doi: 10.1126/sciadv.1700489

Wicker, B., Keysers, C., Plailly, J., Royet, J. P., Gallese, V., and Rizzolatti, G. (2003). Both of us disgusted in My insula: the common neural basis of seeing and feeling disgust. Neuron 40, 655-664. doi: 10.1016/S0896-6273(03) 00679-2

Winner, E., Goldstein, T. R., and Vincent-Lancrin, S. (2013). Art for Art's Sake? The Impact of Arts Education. Paris: OECD Publishing.

Zeman, A., Milton, F., Smith, A., and Rylance, R. (2013). By heart an fMRI study of brain activation by poetry and prose. J. Conscio. Studies, 20, 132-158.

Conflict of Interest: The authors declare that the research was conducted in the absence of any commercial or financial relationships that could be construed as a potential conflict of interest.

Copyright (c) 2020 McDonald, Goldstein and Kanske. This is an open-access article distributed under the terms of the Creative Commons Attribution License (CC BY).

The use, distribution or reproduction in other forums is permitted, provided the original author(s) and the copyright owner(s) are credited and that the original publication in this journal is cited, in accordance with accepted academic practice. No use, distribution or reproduction is permitted which does not comply with these terms. 